\title{
Sustained Natural Apophyseal Glides versus Positional Release Therapy in the Treatment of Chronic Mechanical Neck Dysfunction
}

\author{
Emad Eldin Mohamed ${ }^{1, *}$, Reda kotb Abd Elrazik ${ }^{2}$ \\ ${ }^{1}$ Department of Basic Science, Faculty of Physical Therapy, October 6 University (O6U), Egypt \\ ${ }^{2}$ Department of Physical Therapy for Orthopedics, Faculty of Physical Therapy, Modern University for Technology and Information, \\ Egypt
}

Received August 31, 2020; Revised November 18, 2020; Accepted November 29, 2020

\section{Cite This Paper in the following Citation Styles}

(a): [1] Emad Eldin Mohamed, Reda kotb Abd Elrazik, "Sustained Natural Apophyseal Glides versus Positional Release Therapy in the Treatment of Chronic Mechanical Neck Dysfunction," International Journal of Human Movement and Sports Sciences, Vol. 8, No. 6, pp. 384 - 394, 2020. DOI: 10.13189/saj.2020.080610.

(b): Emad Eldin Mohamed, Reda kotb Abd Elrazik (2020). Sustained Natural Apophyseal Glides versus Positional Release Therapy in the Treatment of Chronic Mechanical Neck Dysfunction. International Journal of Human Movement and Sports Sciences, 8(6), 384 - 394. DOI: 10.13189/saj.2020.080610.

Copyright $@ 2020$ by authors, all rights reserved. Authors agree that this article remains permanently open access under the terms of the Creative Commons Attribution License 4.0 International License

\begin{abstract}
Background: Mechanical neck dysfunction (MND) is a common disorder prevailing among the individuals of different populations. It is characterized by pain and limited range of motion (ROM) which, in turn, affects the activities of daily living and quality of life. Although manual therapy is commonly used in MND treatment to restore a range of motion and reduce pain, some techniques have low evidence in treating MND. Aim: This study was conducted to compare the effect of sustained natural apophyseal glides (SNAGs) with positional release therapy (PRT) on cervical ROM, pain intensity, and functional disability in patients with chronic mechanical neck dysfunction. Methods: One hundred and twenty patients from both genders, where they were divided randomly into three groups. Group A received conventional physical therapy, group B received conventional therapy in addition to SNAGs, and group C received conventional therapy plus PRT three times per week for eight weeks. The universal goniometer was used to measure cervical ROM, numeric pain rating scale (NPRS) was used to measure pain intensity, and neck disability index was used to measure cervical function disability at two intervals, pretreatment and post-treatment. Results: The results showed significant difference in the cervical ROM, NPRS, and NDI between the three groups $(\mathrm{p}<0.001)$ in favor of the group B. Conclusion: SNAGs with conventional physical therapy have been proven to be
\end{abstract}

effective method in treating patients with chronic mechanical neck dysfunction patients.

Keywords Mechanical Neck Pain, Mulligan SNAGs, Positional Release

\section{Introduction}

Chronic mechanical neck dysfunction (CMND) is a type of dysfunctional syndrome affecting the cervical spine, characterized by intermittent cervical pain, pain on palpation of cervical musculature without pathologies extending from the area between superior nuchal line till the first thoracic vertebra [1]. There is irrefutable evidence of an association between mechanical neck pain and muscle dysfunction that, in turn, leads to restriction of end rang of movements and dysfunction of cervical muscles, especially when the cervical spine is loaded [2]. It may not involve cervical muscles alone, but the neighboring thorax and shoulder girdle. [3].

Mechanical neck pain may arise from disorders in the neck, such as neural tissue, uncovertebral or intervertebral joints, discs, bones, periosteum, muscles, and ligaments. It was found that abnormal muscular and ligamentous strength, endurance, and abnormal joint mobility with 
limitation in all cervical ROMs may lead to abnormal biomechanics of body movement, causing the abnormal physical load to various tissues, and thus develop a vicious cycle of pain and dysfunction; therefore, individuals become more susceptible to musculoskeletal injury [4].

Chronic mechanical neck pain can be determined by how long the pain lasts. Some authors classify mechanical neck pain as chronic when lasts for at least three months, while others classify it after only one month [5] or eight weeks of pain symptoms [6].

Myofascial trigger points (MTrPs) are one of the most common symptoms affecting the muscles of the cervical region, especially the upper fiber of trapezius in patients with CMND [7,8]. Recent studies have reported that MTrPs may be responsible for chronic pain in the cervical region which in turn reduces daily function and quality of life. Usually, patients with CMND suffer from a decrease in ROM, pain, and tenderness on the upper trapezius $[9,10]$. As a result of these symptoms, the treatment of CMNPD is different according to therapists, some have used soft tissue and spinal manipulation to decrease tension in the muscle and maintain alignment of the cervical spine, and others have used conventional therapy with or without electrical stimulation in treating CMND [11].

Mulligan techniques and positional release are methods used in the treatment program of chronic neck pain [12]. Mulligan suggested the use of Natural Apophyseal Glides (NAGs), mobilization with movement, and Sustained Natural Apophyseal Glide (SNAG) in the treatment of spinal pain which restore normal movement caused by pain and stiffness $[13,14]$. Although Mulligan technique is one of the manual therapy techniques used to reduce the pain, vertigo, and headache caused by disorders of the cervical spine, few studies demonstrate its effectiveness in chronic neck pain $[15,16]$.

Mulligan [17] reported that when an increase in a pain-free range of movement occurs with a SNAG, it does not only affect the local spinal level being mobilized, but it influences the entire spinal functional unit (SFU). Recently, the use of transverse glides applied to the spinous process is supported by the development of this concept.

Positional release technique (PRT) is an osteopathic treatment technique achieved by placing the part in an ideal position of comfort to decrease the irritability of the tender point and to normalize the tissue associated with dysfunction. This technique is called initially "spontaneous release by positioning" and later "stress and counterpressure". It is eventually known as "positional release". Through this technique, the muscle and dysfunctional joints are pulled away from their restrictive barrier into a position of comfort in the treatment of both musculoskeletal [18] and visceral dysfunctions [19]. The mechanism of this approach is that the brain receives a signal from the shorted muscle causing a decrease in muscle contraction and a decrease in somatic dysfunctions that are hardly treated by other procedures $[20,21]$. Some experts have recommended the use of positional release in the treatment of trigger points ( $\mathrm{TrPs})$ which produce a reduction in tone and hence a release of histamine $[7,8,22]$.

\section{Methodology}

\section{Subjects}

One hundred and twenty patients with CMND (70 females and 50 males) were included in this study as they were diagnosed by orthopedic surgeons. Their ages ranged between 25 and 40 years. They were selected from the hospital of October 6 University in the period from March 2018 to January 2019 and were divided randomly into three groups. Group A $(n=40)$ received conventional physical therapy consisting of heating, strengthening and isometric exercises, group B $(n=40)$ received the same conventional therapy in addition to SNAGs, and group C $(n=40)$ received the same conventional therapy plus positional release. All patients in the three groups received the treatment program three times per week for eight weeks. The study was approved by the Ethical Committee of the Faculty of Physical Therapy, October 6 University (Approval number: O6U.REC.425). The participants signed written consent forms to participate and publish the results of the study, and they were allocated according to these criteria: Neck pain lasting more than 3 months, local tenderness of the upper fibers of trapezius, stiffness and muscle spasm, while patients with cervical trauma, inflammation, degenerative changes, congenital malformation, disc herniation, cervical spine surgery or stenosis, metabolic, systemic disorders, cancer, or arm pain were excluded from this study.

\section{Randomization method}

Opaque, sealed and stapled envelopes were used in random allocation of patients. Each envelope contains the program of treatment, either conventional therapy, SNAGS or PRT with a foil of aluminum inside the envelope to hide any information. All participants were asked to write their names and birth dates on the envelope. This method was done by another physiotherapist to avoid allocation bias. After assessment of enrolled participants, all envelopes were opened to allocate the intervention.

\section{Procedures}

\section{A) Assessment procedures}

Before starting the treatment, selected patients were checked for any abnormalities in their skin and physical status. Cervical ROM, pain intensity, and functional 
disability were then measured by the following instrumentation tools at baseline and after eight weeks of treatment.

1. Universal goniometer: It was used to measure cervical ROM (flexion-extension-side bending and rotation). It is a reliable and valid tool used to assess cervical ROM] [23]. The patients were seated in a sitting position with their backs straight and arms folded across their chests to decrease any substitution from the thoracic region.

2. Numeric pain rating scale (NPRS): It was used to measure pain intensity and it is a scale of 11 points ranging from 0 to 10 points. Point ' 0 ' is related to "no pain," while point ' 10 ' is related to "worst pain". Each patient was asked to select a point describing the severity of the pain. NPRS is a reliable tool and has good sensitivity to pain measuring [24].

3. Neck disability index: It was used to measure the functional disability of the cervical spine. It gives feedback information about the relation between neck pain and the ability of patients to manage every day. This questionnaire consists of 10 sections; each section contains 5 multiple questions. Each patient was asked to choose one statement that relates to his/her neck disability. A score of 5 in each section indicates great disability, while the score of 0 indicates no functional disability. The score of each section was collected for calculating the functional disability from the total score of NDI which was 50 points. The percentage of NDI was calculated according to the score of patient answers. The percentage classified as $0-8 \%$ means there is no disability ( $0-4$ of patient score ), $10-28 \%$ is mild (514 of patient score ), $30-48 \%$ is moderate $(15-24$ of patient score), $50-68 \%$ is severe disability ( $25-34$ of the patient score) and $72 \%$ or more is considered complete disability ( 35 or more of patient score) [25].

\section{B) Treatment procedures}

After assessment of all patients of the three groups, they performed the treatment exercises as the following.

\section{Conventional physical therapy}

It included infrared radiation for 15 minutes with the patient sitting on a high-back supported chair, then strengthening exercises for neck flexors, extensors and muscles of side bending for 10 repetitions in 3 sets and isometric exercises for the same muscles, 10 repetitions for 3 sets per session, each isometric exercise was held for 6 seconds to avoid muscle fatigue. The exercises lasted for 24 sessions, 3 sessions per week over eight weeks.

\section{SNAGs}

The patient was asked to sit on a low back support chair to make the cervical region in a vertical position (weight-bearing) with the therapist standing behind the patient. It was useful to have the patient sit facing a large wall mounted mirror to enable the therapist to observe the patient's facial expressions, and therefore, his/her reactions during the first stages of the technique. A posteroanterior (PA) glide in line with the facet plane was applied gently to the spinous process or articular pillar of any of the motion segments between C3-7 by placing the medial border of the right thumb on the spinous process or articular pillar and the pad of the left thumb placed perpendicular to the nail of the right thumb. During this glide, the patient was asked to actively move his/her neck toward the direction that elicited symptoms. In case of symptom-free, the patient applied overpressure to the end of the restricted range of flexion, extension, rotations, and side bending. This application was repeated six times for three sets.

\section{Positional release technique}

\section{Upper trapezius}

The patient was in a relaxed supine position with the therapist standing on the affected side; the trigger point was identified along with the upper trapezius. The pressure was applied by the therapist's thumb. The head of the patient was laterally flexed toward the affected side, then the therapist abducted the patient's shoulder 90 degrees with slight rotation or flexion to fine-tune. In that position, the therapist maintained pressure to the tender point with his thumb for the 90 seconds to release tension in the tender point followed by returning the head passively to the neutral position.

\section{Sternocleidomastoid}

The patient was in a relaxed supine position with the therapist standing on the affected side. After the therapist had identified the tender point in the muscle, he moved the patient's head towards the tender point and then pressed with his thumb for 90 seconds to release the tension, then he passively returned the head to the neutral position.

The PRT was repeated either for upper trapezius or sternocleidomastoid for 3 times with 20 seconds relaxation time as intervals between repetitions.

\section{Data Analysis}

Sample size calculation was performed prior to the study based on data of pilot study using cervical ROM, pain intensity (NPRS) and functional disability (NDI) as the primary outcome using G*POWER statistical software (version 3.1.9.2; Franz Faul, Universitat Kiel, Germany) [F tests- MANOVA: Repeated measures, within-between interaction, $\alpha=0.05, \beta=0.2$, effect size $=0.29$ ] and revealed that the appropriate sample size for this study was $\mathrm{N}=120$.

Descriptive statistics and ANOVA test were conducted for comparison of subject characteristics among the three 
groups. Normal distribution of data was checked using the Shapiro-Wilk test for all variables. Levene's test for homogeneity of variances was conducted to test the homogeneity between groups. Mixed MANOVA was performed to compare within and between groups effects on neck ROM, NPRS and NDI. Post-hoc tests using the Bonferroni correction were carried out for subsequent multiple comparisons. The level of significance for all statistical tests was set at $\mathrm{p}<0.05$. All statistical analysis was conducted through the statistical package for social studies (SPSS) version 25 for windows (IBM SPSS, Chicago, IL, USA).

\section{Results}

\section{Subject characteristics:}

Table (1) showed the subject characteristics of the group A, B and C. There was no significant difference between groups in age, weight, height and BMI ( $\mathrm{p}>$ 0.05).

\section{Effect of treatment on neck ROM, NPRS and NDI:}

There was a significant interaction of treatment and time $(\mathrm{F}=102.31, \mathrm{p}=0.001)$. There was a significant main effect of time $(F=8087.98, p=0.001)$. There was a significant main effect of treatment $(\mathrm{F}=132.72, \mathrm{p}=$ $0.001)$.

\section{- Within group comparison:}

There was a significant increase in neck ROM post treatment compared with that pretreatment in the groups $\mathrm{A}$, B and C $(p<0.001)$. Group B showed the highest percent of improvement and was followed by group C, while group A showed the lowest percent of improvement.

The percent of increase in neck ROM of group A was 35.76, 35.14, 41.04, 40.24, 40.67 and 37.96\% for flexion, extension, right rotation, left rotation, right bending and left bending, respectively; while the percent of improvement in group B was 64.86, 73.79, 77.28, 72.44, 67.64 , and $70.6 \%$ or flexion, extension, right rotation, left rotation, right bending and left bending, respectively. The percent of improvement in group C was 48.06, 51.56, 53.70, 51.60, 51.63 and 51.64\% flexion, extension, right rotation, left rotation, right bending and left bending respectively.

In addition, there was a significant decrease in NPRS, and NDI of the three groups post-treatment compared with that of pretreatment $(\mathrm{p}<0.001)$. The percent of improvement of NPRS and NDI for group A was 33.49 and $16.85 \%$ respectively, and for group B was 66.46 and $53.20 \%$, respectively; while percent for group C was 47.93 and $41.47 \%$, respectively. (table 2, figure $1-3$ ).

\section{- Between groups comparison:}

There was no significant difference between groups in all pretreatment parameters $(\mathrm{p}>0.05)$.

There was a significant increase in neck ROM of group B compared with that of group A and C post-treatment (p $<0.001$ ) and a significant increase in neck ROM of group $\mathrm{C}$ compared with that of group A post-treatment ( $\mathrm{p}<$ 0.001). There was a significant decrease in NPRS and NDI of group B compared with that of group A and C post-treatment $(p<0.001)$ and a significant decrease in NPRS and NDI of group C compared with that of group A post-treatment $(\mathrm{p}<0.001)$. (table 3 , figure $1-3)$

Table 1. Basic characteristics of participants

\begin{tabular}{|lcccc|}
\hline & Group A & Group B & Group C & \multirow{2}{*}{ p-value } \\
\cline { 2 - 4 } & mean \pm SD & mean \pm SD & mean \pm SD & \\
\cline { 2 - 4 } Age (years) & $34.02 \pm 4.73$ & $35.22 \pm 3.68$ & $34.42 \pm 3.75$ & 0.41 \\
Weight (kg) & $82.17 \pm 2.81$ & $82.92 \pm 2.04$ & $83.12 \pm 2.78$ & 0.22 \\
Height (cm) & $164.2 \pm 3.91$ & $165.4 \pm 3.84$ & $165.8 \pm 3.71$ & 0.15 \\
BMI (kg/m) & $30.53 \pm 1.8$ & $30.36 \pm 1.66$ & $30.28 \pm 1.8$ & 0.81 \\
\hline
\end{tabular}

$\mathrm{SD}$, standard deviation; p-value, level of significance 

in the Treatment of Chronic Mechanical Neck Dysfunction

Table 2. Mean neck ROM, NPRS and NDI pretreatment and post-treatment of group A, B and C:

\begin{tabular}{|c|c|c|c|c|c|}
\hline & Pretreatment & Post-treatment & & & \\
\hline & mean \pm SD & mean \pm SD & MD $(95 \% \mathrm{CI})$ & $\%$ of change & $P$ value \\
\hline \multicolumn{6}{|c|}{ ROM (degrees) } \\
\hline \multicolumn{6}{|l|}{ Flexion } \\
\hline Group A & $24.05 \pm 1.41$ & $32.65 \pm 0.97$ & $-8.6(-9.06:-8.13)$ & 35.76 & 0.001 \\
\hline Group B & $23.85 \pm 1.14$ & $39.32 \pm 0.72$ & -15.47 (-15.93: -15.01) & 64.86 & 0.001 \\
\hline Group C & $24.45 \pm 1.2$ & $36.2 \pm 0.75$ & $-11.75(-12.21:-11.28)$ & 48.06 & 0.001 \\
\hline \multicolumn{6}{|l|}{ Extension } \\
\hline Group A & $27.32 \pm 1.04$ & $36.92 \pm 1.14$ & -9.6 (-10.04: -9.15) & 35.14 & 0.001 \\
\hline Group B & $27.2 \pm 0.99$ & $47.27 \pm 1.01$ & -20.07 (-20.52: -19.63) & 73.79 & 0.001 \\
\hline Group C & $26.9 \pm 0.92$ & $40.77 \pm 1.27$ & $-13.87(-14.32:-13.43)$ & 51.56 & 0.001 \\
\hline \multicolumn{6}{|c|}{ Right rotation } \\
\hline Group A & $33.02 \pm 1.05$ & $46.57 \pm 0.95$ & $-13.55(-14:-13.09)$ & 41.04 & 0.001 \\
\hline Group B & $32.7 \pm 1.2$ & $57.97 \pm 1.12$ & -25.27 (-25.73: -24.82) & 77.28 & 0.001 \\
\hline Group C & $32.87 \pm 1.04$ & $50.52 \pm 1.01$ & $-17.65(-18.1:-17.2)$ & 53.70 & 0.001 \\
\hline \multicolumn{6}{|l|}{ Left rotation } \\
\hline Group A & $34.12 \pm 1.15$ & $47.85 \pm 1.25$ & $-13.73(-14.23:-13.21)$ & 40.24 & 0.001 \\
\hline Group B & $33.82 \pm 0.98$ & $58.32 \pm 1.07$ & $-24.5(-25:-24)$ & 72.44 & 0.001 \\
\hline Group C & $33.72 \pm 1.08$ & $51.12 \pm 1.36$ & $-17.4(-17.9:-16.89)$ & 51.60 & 0.001 \\
\hline \multicolumn{6}{|c|}{ Right bending } \\
\hline Group A & $25.45 \pm 1.19$ & $35.8 \pm 1.4$ & -10.35 (-10.88: -9.81) & 40.67 & 0.001 \\
\hline Group B & $26.02 \pm 1.25$ & $43.62 \pm 1.27$ & $-17.6(-18.13:-17.06)$ & 67.64 & 0.001 \\
\hline Group C & $25.82 \pm 1.3$ & $39.15 \pm 1.07$ & $-13.33(-13.86:-12.78)$ & 51.63 & 0.001 \\
\hline \multicolumn{6}{|l|}{ Left bending } \\
\hline Group A & $25.42 \pm 1.23$ & $35.07 \pm 1.16$ & $-9.65(-10.22:-9.08)$ & 37.96 & 0.001 \\
\hline Group B & $25.95 \pm 1.28$ & $44.27 \pm 1.28$ & $-18.32(-18.9:-17.75)$ & 70.6 & 0.001 \\
\hline Group C & $25.37 \pm 1.23$ & $38.47 \pm 1.01$ & $-13.1(-13.67:-12.52)$ & 51.64 & 0.001 \\
\hline \multicolumn{6}{|l|}{ NPRS } \\
\hline Group A & $6.27 \pm 0.68$ & $4.17 \pm 0.63$ & 2.1 (1.84: 2.35) & 33.49 & 0.001 \\
\hline Group B & $6.32 \pm 0.8$ & $2.12 \pm 0.64$ & 4.2 (3.94: 4.45) & 66.46 & 0.001 \\
\hline Group C & $6.05 \pm 0.67$ & $3.15 \pm 0.66$ & 2.9 (2.64: 3.15) & 47.93 & 0.001 \\
\hline \multicolumn{6}{|l|}{ NDI (\%) } \\
\hline Group A & $22.97 \pm 1.32$ & $19.1 \pm 0.9$ & 3.87 (3.39: 4.35) & 16.85 & 0.001 \\
\hline Group B & $22.65 \pm 1.07$ & $10.6 \pm 1.03$ & 12.05 (11.57: 12.53) & 53.20 & 0.001 \\
\hline Group C & $22.5 \pm 1.22$ & $13.17 \pm 1.03$ & 9.33 (8.84: 9.8) & 41.47 & 0.001 \\
\hline
\end{tabular}

SD, Standard deviation; MD, Mean difference; CI, Confidence interval; p-value, Level of significance 
Table 3. Comparison of neck ROM, NPRS and NDI post treatment between group A, B and C:

\begin{tabular}{|c|c|c|c|}
\hline & Group A vs group B & Group A vs group C & Group B vs group $C$ \\
\hline \multicolumn{4}{|l|}{ Flexion } \\
\hline \multirow[t]{2}{*}{ MD (95\% CI) } & $-6.67(-7.12:-6.22)$ & $-3.55(-4:-3.1)$ & 3.12 (2.67: 3.57) \\
\hline & $\mathrm{p}=0.001$ & $\mathrm{p}=0.001$ & $\mathrm{p}=0.001$ \\
\hline \multicolumn{4}{|l|}{ Extension } \\
\hline \multirow[t]{2}{*}{ MD (95\% CI) } & -10.35 (-10.97: -9.72) & $-3.85(-4.47:-3.22)$ & 6.5 (5.87: 7.12) \\
\hline & $\mathrm{p}=0.001$ & $p=0.001$ & $\mathrm{p}=0.001$ \\
\hline \multicolumn{4}{|l|}{ Right rotation } \\
\hline \multirow[t]{2}{*}{ MD (95\% CI) } & $-11.4(-11.96:-10.83)$ & $-3.95(-4.51:-3.38)$ & 7.45 (6.88: 8.01) \\
\hline & $\mathrm{p}=0.001$ & $\mathrm{p}=0.001$ & $\mathrm{p}=0.001$ \\
\hline \multicolumn{4}{|l|}{ Left rotation } \\
\hline \multirow[t]{2}{*}{ MD (95\% CI) } & -10.47 (-11.14: -9.8) & $-3.27(-3.94:-2.6)$ & 7.2 (6.53: 7.87) \\
\hline & $p=0.44$ & $\mathrm{p}=0.001$ & $\mathrm{p}=0.001$ \\
\hline \multicolumn{4}{|l|}{ Right bending } \\
\hline \multirow[t]{2}{*}{ MD (95\% CI) } & $-7.82(-8.5:-7.14)$ & $-3.35(-4.03:-5.66)$ & 4.47 (3.8: 5.15) \\
\hline & $\mathrm{p}=0.001$ & $\mathrm{p}=0.001$ & $\mathrm{p}=0.001$ \\
\hline \multicolumn{4}{|l|}{ Left bending } \\
\hline \multirow[t]{2}{*}{ MD (95\% CI) } & $-9.2(-9.82:-8.57)$ & $-3.4(-4.02:-2.77)$ & 5.8 (5.17: 6.42) \\
\hline & $\mathrm{p}=0.001$ & $\mathrm{p}=0.001$ & $\mathrm{p}=0.001$ \\
\hline \multicolumn{4}{|l|}{ NPRS } \\
\hline \multirow[t]{2}{*}{ MD (95\% CI) } & 2.05 (1.69: 2.4) & 1.02 (0.67: 1.37) & $-1.03(-1.37:-0.67)$ \\
\hline & $\mathrm{p}=0.001$ & $\mathrm{p}=0.001$ & $\mathrm{p}=0.001$ \\
\hline \multicolumn{4}{|l|}{ NDI } \\
\hline \multirow[t]{2}{*}{ MD (95\% CI) } & 8.5 (7.96: 9.03) & 5.93 (5.38: 6.46) & $-2.57(-3.11:-2.03)$ \\
\hline & $\mathrm{p}=0.001$ & $\mathrm{p}=0.001$ & $\mathrm{p}=0.001$ \\
\hline
\end{tabular}

MD, Mean difference; CI, Confidence interval; p-value, Level of significance

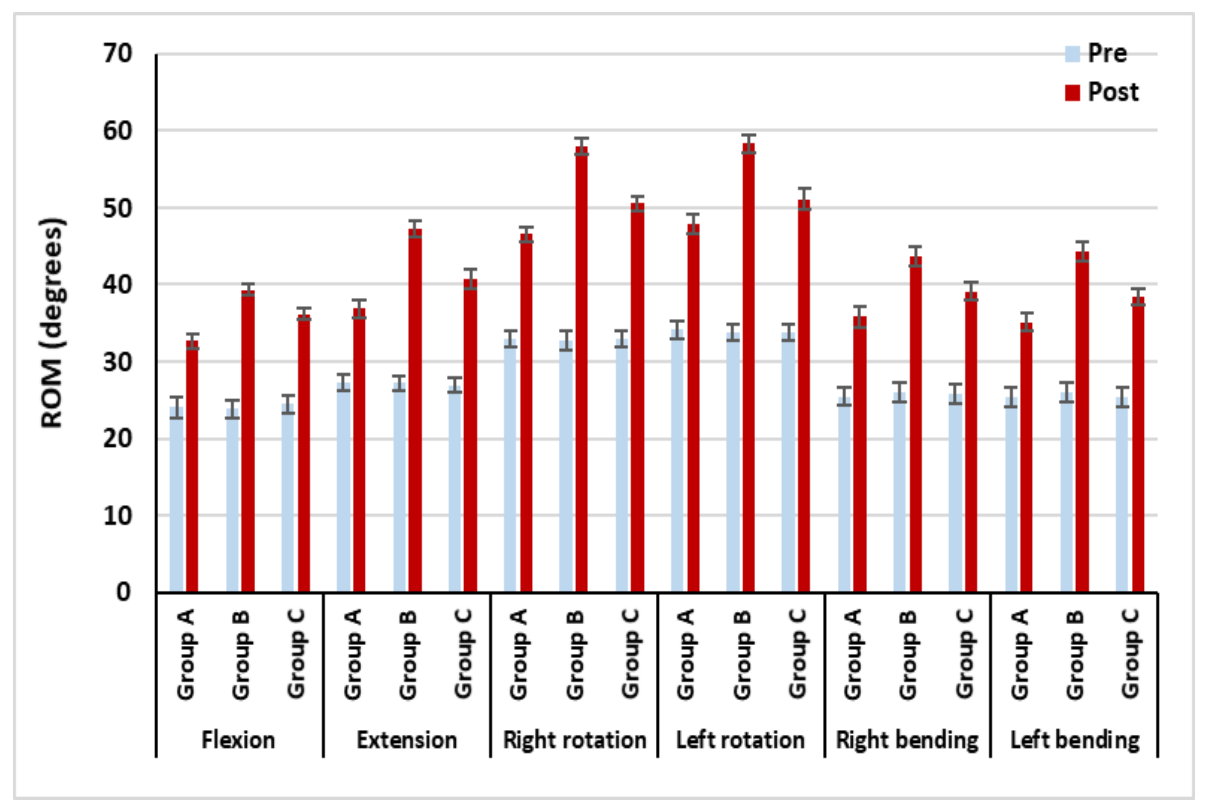

Figure 1. Mean neck ROM pretreatment and post-treatment of group A, B and C 


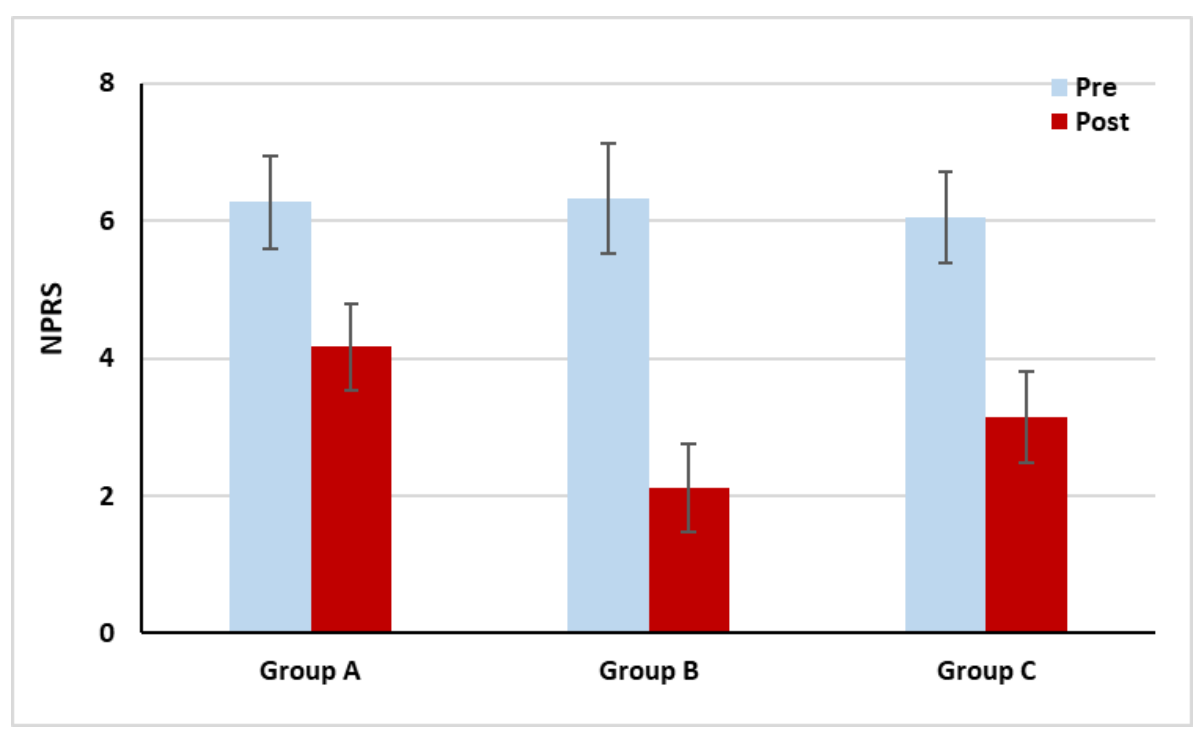

Figure 2. Mean NPRS pretreatment and post-treatment of group A, B and C

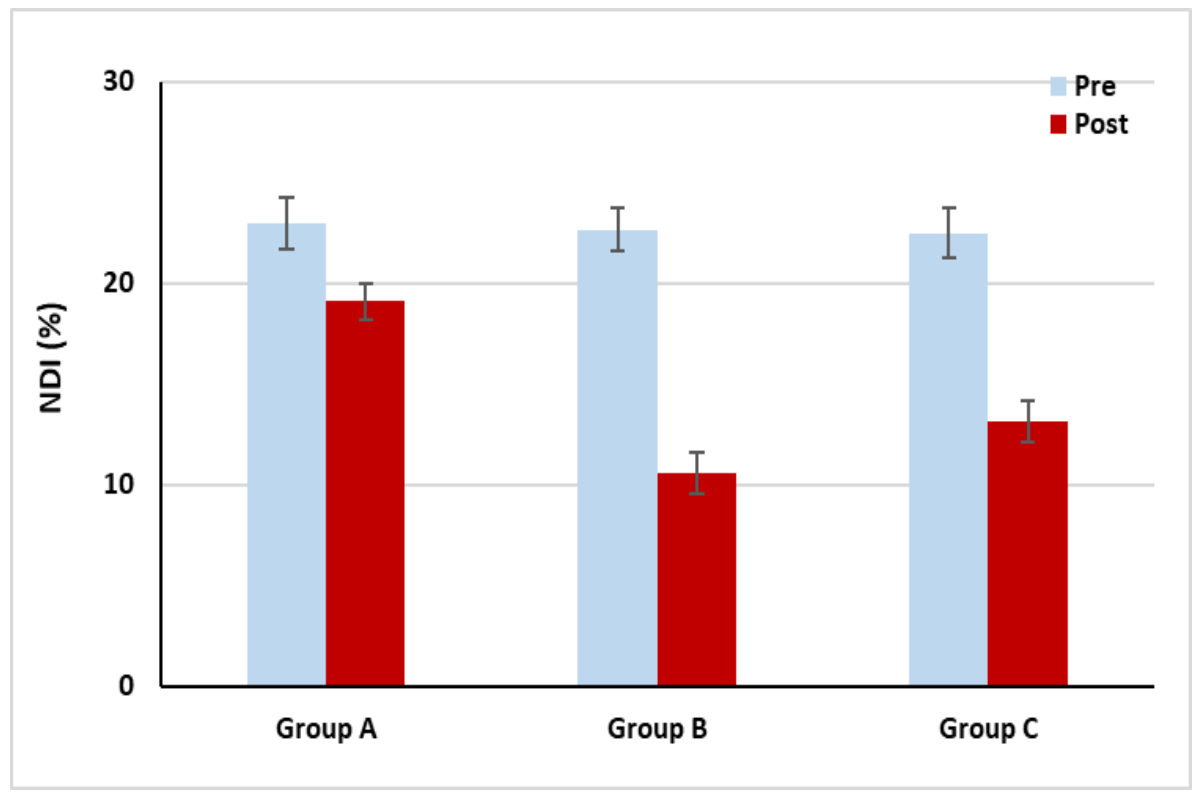

Figure 3. Mean NDI pretreatment and post-treatment of group A, B and C

\section{Discussion}

Based on the results of the current study, the statistical analysis showed that there was a statistically significant difference in the mean values of post cervical ROM, pain intensity and functional disability between the groups in favor of the group B who received SNAGs in addition to conventional physical therapy. The percentages of improvement in the three groups were, regarding flexion $35.76 \%, 64.86 \%$ and $48.06 \%$, extension $35.14 \%$, $73.79 \%$ and $51.56 \%$, rotation to right $41.04 \%, 77.28 \%$ and $53.70 \%$, rotation to left $40.24 \%, 72.44 \%$ and $51.60 \%$, side bending to right $40.67 \%, 67.64 \%$ and $51.63 \%$, side bending to left $37.96 \%, 70.6 \%$ and $51.64 \%$, pain intensity $33.49 \%, 66.46 \%$ and $47.93 \%$, and functional disability score $16.85 \%, 53.20 \%$ and $41.47 \%$ for groups A, B and C, respectively.

Neck pain is most commonly between people who work with a neck bent-forward posture which could, in turn, result in referred pain to the upper limb that could affect the function of both cervical region and upper limb [26]. Therefore, to evaluate and treat pain and functional disability in chronic mechanical neck pain patients, a valid and reliable tool should be used to measure pain and functional disability at baseline and after treatment to detect changes that occur in cervical region as rehabilitation progresses are needed.

Vernon [27] evaluated the validity and reliability of the neck disability index in comparison to McGill pain questionnaire and concluded that NDI has a high degree 
of validity and reliability compared to McGill pain questionnaire. Therefore, NDI was used to evaluate the functional disability of the cervical spine in the current study to confirm the results of the past studies.

Ferraz et al. [28] stated that the NPRS is a valid and reliable tool in the assessment of pain intensity and highly correlated with the Visual Analogue Scale (VAS) for patients with chronic pain conditions. Patients in these chronic cases prefer the NPRS over other scales that measure pain intensity, including the VAS, due to simplicity and ease of completion [29,30,31].

Shamsi et al. [32] compared between universal goniometer and electro-goniometer and concluded that both goniometers have a good reliability in evaluation of joint ROM thus can be used in experimental studies.

Regarding the efficacy of exercise therapy on improvement of cervical ROM, pain and function results enrolled in the current agreed with a systematic review that was conducted by Lee and Kim [33] who conducted an experimental study on forty-six patients with chronic neck pain, they were treated three times per week for 10 weeks and the treatment lasting 35 minutes in the session. Patients were divided into three groups, one control group (group C) and two experimental groups (group A and B); group $A$ received thoracic manipulation plus strengthening and isometric exercises, group B received strengthening and isometric exercises, and group $\mathrm{C}$ received active exercise. ROM of the cervical spine, pain intensity, and neck disability index, all were measured before and after the intervention. The results concluded that exercise therapy for the neck revealed significant improvement in neck ROM, pain and function, and adding manipulation to exercise therapy seems to be more effective in chronic neck pain patients.

The findings of the current study are consistent with the previous studies demonstrating the effective role of manual therapy and exercises in the treatment of mechanical neck disorders. Gross et al. [34] found that the use of endurance exercises combined with strengthening exercises is beneficial for the treatment of mechanical neck disorders.

Gross et al. [35] also demonstrated that the use of exercise alone or combination with manual therapy has a positive effect on decreasing pain and improving function after the short or long term. A study by Sarig-Bahat [36] showed that proprioceptive exercises and resisted exercises have strong evidence in the treatment of chronic or frequent neck disorders.

In contrast to present findings, Verhagen et al. [37] found that there was no statistically significant effect of active or passive exercises on relieving pain and improving function in chronic neck disorders.

Regarding the efficacy of mulligan manipulations on the improvement of cervical ROM, pain, and function, results of the present study are compatible with Rajesh [38], who reported that Mulligan mobilization is superior to Maitland and conventional exercise in improving cervical lateral bending ROM in mechanical neck pain patients. This result also agrees with Kotb [39] who reported that SNAGs mobilization showed significant improvement in the level of pain and lumbar spine extension ROM than Maitland mobilization after successive 4 weeks treatment period. Also, these agree with Ahmed et al. [40] who conducted a study on 49 males with chronic cervical pain, in which the results of their study indicated that SNAGs mobilization with movement can improve ROM and decrease pain in cervical spine.

The mechanism of symptom relief in the cervical spine after SNAGs may be due to both mechanical and reflexogenic effects [41]. The rapid mechanical effect of pain relief is based on the faulty position of bone and the ability of SNAGS to mobilize and correct these faults. [42]. Application of the sustained glide in cervical SNAG may cause repositioning of the superior facet by distracting the ipsilateral functional spinal unit, which, in turn, helps decrease pain during active ROM [43].

Positional release therapy in addition to conventional exercises selected for the current study produced significant improvement in cervical ROM, pain intensity, and functional disability. The treatment time of positional release (90 seconds) was chosen in the current study based on the evidence available. Previous researches suggested the use of 90s time of treatment for PRT as it decreases muscle spindle activity and gamma firing level $[44,45,46]$

Bode's Pardo et al. [45] stated that the use of active trigger point therapy can increase active cervical ROM in patients with the upper trapezius and sternocleidomastoid muscles trigger points than those received simulated therapy. D'Ambrogio et al. [46] reported that PRT can produce a normalization of muscle hypertonicity and flexibility of the restricted fascia that, in turn, improve ROM and circulation, decrease pain, and functional disability. Wong et al. [47] conducted a study on 49 subjects with bilateral hip tender points, they were divided randomly into 3 groups; group received PRT and group received stretching, strengthening and isometric exercises and the last group received PRT plus previous exercises. It was stated that pain and functional disability were improved in all groups with favor to PRT plus exercise group. Lewis et al. [48] showed that all patients received PRT for the treatment of low back pain registered a decrease in pain and functional disability following PRT intervention, they suggested that PRT in treating pain and function especially in low back pain cases need more studies to examine the efficacy of this technique.

Denise Deig [49] used Surface EMG activity to record changes in the upper fiber of trapezius before and after positional release therapy and found that PRT has a positive effect on improving cervical ROM and decreasing pain in patients who suffer from the upper 
trapezius trigger point. This improvement that appeared in outcomes after PRT application may be related to the inhibition of the facilitated segment of the spinal cord by decreasing gamma discharge activity that, in turn, can normalize nerve conduction velocity between extrafusal and intrafusal muscle fiber [50].

\section{Conclusions}

It was concluded that adding SNAGS to conventional therapy is more effective in improving cervical ROM, decreasing pain and reducing functional disability in patients with chronic mechanical neck dysfunction than conventional therapy alone or conventional therapy plus positional release technique.

\section{Acknowledgment}

We express our sincere gratitude to all the patients, orthopedic surgeons and physiotherapists at October 6 University for their kind cooperation during this study.

\section{Conflict of Interest}

No conflict of interest

\section{REFERENCES}

[1] La Touche R, Fernández-de-Las-Peñas C, Fernández-Carnero J, Díaz-Parreño S, Paris-Alemany A, Arendt-Nielsen L. Bilateral mechanical-pain sensitivity over the trigeminal region in patients with chronic mechanical neck pain. J Pain. 2010;11(3):256-263. doi:10.1016/j.jpain. 2009.07.003

[2] O`Leary S, Falla D, Elliott and Jull G. Muscle dysfunction in cervical spine pain: Implications for assessment and management. Journal of Orthopaedic \& Sports Physical Therapy. 2009;39(5) ,324-333. doi:10.2519/jospt.2009.2872

[3] Jull G, Sterling M, Falla D, Treleaven J, O'Leary S. Whiplash, Headache, and Neck Pain: Research- Based Directions for Physical Therapies. Edinburgh, UK: Elsevier. 1st ed, 2008, pp. 1-260. https://www.elsevier.com/books/w hiplash-headache-and-neck-pain/jull/978-0-443-10047-5.

[4] Paungmali A, O'Leary S, Souvlis T, Vicenzino B. Hypoalgesic and sympathoexcitatory effects of mobilization with movement for lateral epicondylalgia. Phys Ther. 2003; 83(4):374-383. https://pubmed.ncbi.nlm.nih.gov/12665408/

[5] Merskey H, Bogduk N. Task Force on Taxonomy. Classification of Chronic Pain: Descriptions of Chronic Pain Syndromes and Definitions of Terms. Seattle, WA: IASP Press, 1994, 2nd ed, pp. 9-238. https://s3.amazonaws.com/r dcmsiasp/files/production/public/Content/ContentFolders/P ublications2/FreeBooks/Classification-of-Chronic-Pain.pdf.
[6] Vernon $\mathrm{H}$, Humphreys BK. Chronic mechanical neck pain in adults treated by manual therapy: a systematic review of change scores in randomized controlled trials of a single session. J Man Manip Ther. 2008;16(2):E42-E52. https://www.ncbi.nlm.nih. gov/pmc/articles/PMC2565115/.

[7] Fernández-de-las-Peñas C, Cuadrado ML, Arendt-Nielsen L, Simons DG, Pareja JA. Myofascial trigger points and sensitization: an updated pain model for tension-type headache. Cephalalgia. 2007;27(5):383-393. doi:10.1111/j. 1468-2982.2007.01295.x.

[8] Muñoz-Muñoz, S., MuñozGarcía, M. T., Alburquerque-Sendín, F., Arroyo-Morales, M., Fernández-de-las-Peñas, C. Myofascial trigger points, pain, disability, and sleep quality in individuals with mechanical neck pain. Journal of Manipulative \& Physiological Therapeutics. 2012; 35(8), 608-613. doi:10.1016/j.jmpt.201 2.09.003.

[9] Tsakitzidis, G., Remmen, R., Dankaerts, W., Van Royen, P. Non-specific neck pain and evidence-based practice. European Scientific Journal, ESJ. 2008; 9(3). DOI: https://doi.org/10.19044/esj.2013.v9n3p\%25p

[10] Tsakitzidis, G., Remmen, R., Peremans, L., Van Royen, P., Duchesnes, C., Paulus, D., Eyssen, M. Non-specific neck pain: diagnosis and treatment. Good Clinical Practice (GCP). KCE Reports C. 2009; 119. https://kce.fgov.be/sites/default/ files/atoms /files /d20091027356.pdf.

[11] Gross, A. R., Kay, T., Hondras, M., Goldsmith, C., Haines, T., Peloso, P., Hoving, J. Manual therapy for mechanical neck disorders: a systematic review. Manual therapy. 2002;7(3), 131-149. doi:10.1054/math.2002.0465.

[12] Pérez, H. I., Perez, J. L. A., Martinez, A. G., La Touche, R., Lerma-Lara, S., Gonzalez, N. C., Fernández-Carnero, J. Is one better than another? A randomized clinical trial of manual therapy for patients with chronic neck pain. Manual therapy. 2014; 19(3), 215-221. doi:10.1016/j.math.2013.12. 002 .

[13] Mulligan, B. R. Manual therapy: NAGS, SNAGS, MWMS etc. 4th. Wellington: Plane View Services. 1999, $4^{\text {th }}$ ed, pp.68-86. https://www.amazon.com/Manual-Therapy-N ags-Snags-Mwms/dp/0473057654.

[14] Hing, W., Hall, T., Rivett, D. A., Vicenzino, B., Mulligan, B. The Mulligan Concept of Manual Therapy eBook: Textbook of Techniques. Elsevier Health Sciences. 2015, $1^{\text {st }}$ ed, pp.55-70. https://www.semanticscholar.org/pa per/The-Mulligan-Concept-of-Manual-Therapy\%3A-Textb ook-of-Hing Hall/64d6994 cd389277fe7a 6a2fb3ffb 55b 6 fb6cb5d3

[15] Tachii, R., Sen, S., Arfath, U. short-term effect of sustained natural apophyseal glides on cervical joint position sense, pain and neck disability in patients with chronic neck pain. International Journal of Therapies and Rehabilitation Research. 2015; 4(4), 244. DOI: 10.5455/ijtrr.00000097.

[16] Kumar D. A study on the efficacy of mulligan concept in cervical spine pain and stiffness. 2013. http://hdl.handle.net /10603/10445.

[17] Mulligan BR. Manual Therapy NAGs, SNAGs, MWM ect. New Zealand Plane View Services Ltd. 2004, $5^{\text {th }}$ ed, pp. 51- 66. https://www.amazon.com/Manual-Therapy-NAGSSNAGS-MWMS/dp/047601154X. 
[18] Prasant NP,Anand H, Khatri SM. Comparison of muscle energy technique and positional release therapy in acute low back pain - RCT. Indian Journal of Physiotherapy and Occupational Therapy. 2010;4:2. http://www.i-scholar.in/in dex.Php /ijpot/article/view/47150.

[19] Weiselfish, Giammatteo S. Giammatteo T. Integrative Manual Therapy for the Autonomic Nervous System and Related Disorders: Utilizing Advanced Strain and Counter Strain Technique; Berkeley, California, USA: North Atlantic Books, 1997, pp.9-24. https://www.amazon.com/Sharon-W eiselfish-Giammatteo-Integrative-Autonomic-Counterstrain /dp/B01FMVXPUI

[20] Wynne M M, Burns JM, Eland D, Conatser RR, Howell J N. Effect of Counter strain on Stretch Reflexes, Hoffmann Reflexes, and Clinical Outcomes in Subjects with Plantar Fasciitis. J Am Osteopath Assoc. 2006;106(9):547-556. https://pubmed.ncbi.nlm. nih.gov/17079524/.

[21] Meseguer AA, Fernández-de-las-Peòas C, NavarroPoza JL, Rodrìguez-Blanco C, Gandia JJB. Immediate effects of the strain-counter strain technique in local pain evoked by tender points in the upper trapezius muscle. Clin Chiropr. 2006; 9(3): 112-118. https://doi.org/10.1016/j.clch.2006.06. 003

[22] Charles Carvalho, S., V. Babu. K, S. Kumar .N, and A. .V .R. "EFFECT OF POSITIONAL RELEASE TECHNIQUE IN SUBJECTS WITH SUBACUTE TRAPEZITIS”. International Journal of Physiotherapy.2014; 1(2), 91-99. h ttps://www.ijphy.org/index.php/journal/article/view/19.

[23] Farooq MN, Mohseni Bandpei MA, Ali M, Khan GA. Reliability of the universal goniometer for assessing active cervical range of motion in asymptomatic healthy persons. Pak J Med Sci. 2016; 32(2): 457-461. doi: http://dx.doi.org/10.12669/pjms .322.8747.

[24] Williamson A, Hoggart B. Pain: a review of three commonly used pain rating scales. J Clin Nurs. 2005;14(7):798-804. doi:10.1111/j.1365-2702.2005.01121.x.

[25] Vernon H, Mior S. The Neck Disability Index: a study of reliability and validity [published correction appears in J Manipulative Physiol Ther 1992 Jan;15(1):followi]. J Manipulative Physiol Ther. 1991;14(7):409-415. https://pubmed.ncbi.nlm.nih.gov/ 1834753.

[26] Hanvold TN, Veiersted KB, Waersted M. A prospective study of neck, shoulder, and upper back pain among technical school students entering working life. J Adolesc Health. 2010; 46(5): 488-494. doi:10.1016/j.jadohealth.200 9.11.200.

[27] Vernon H. The Neck Disability Index: state-of-the-art, 1991-2008. J Manipulative Physiol Ther. 2008;31(7):491-502. doi:10.1016/j.jmpt.2008.08.006.

[28] Ferraz MB, Quaresma MR, Aquino LR, Atra E, Tugwell P, Goldsmith $\mathrm{CH}$. Reliability of pain scales in the assessment of literate and illiterate patients with rheumatoid arthritis. J Rheumatol. 1990; 17(8): 1022-1024. https://pubmed.ncbi.nl m. nih.gov/2213777.

[29] de C Williams AC, Davies HT, Chadury Y. Simple pain rating scales hide complex idiosyncratic meanings. Pain. 2000;85(3):457-463. doi:10.1016/s0304-3959(99)00 299-7.

[30] Hawker GA, Davis AM, French MR, et al. Development and preliminary psychometric testing of a new OA pain measure--an OARSI/OMERACT initiative. Osteoarthritis Cartilage. 2008; 16(4): 409-414. doi:10.1016/j.joca.2007.12 .015 .

[31] Hush JM, Refshauge KM, Sullivan G, De Souza L, McAuley $\mathrm{JH}$. Do numerical rating scales and the Roland-Morris Disability Questionnaire capture changes that are meaningful to patients with persistent back pain?. Clin Rehabil. 2010; 24(7): 648-657. doi:10.1177/026921 5510367975.

[32] Shamsi M, Mirzaei M, Khabiri SS. Universal goniometer and electro-goniometer intra-examiner reliability in measuring the knee range of motion during active knee extension test in patients with chronic low back pain with short hamstring muscle. BMC Sports Sci Med Rehabil. 2019;11:4. Published 2019 Mar 22. doi:10.1186/s13102-01 9-0116-x.

[33] Lee KW, Kim WH. Effect of thoracic manipulation and deep craniocervical flexor training on pain, mobility, strength, and disability of the neck of patients with chronic nonspecific neck pain: a randomized clinical trial. J Phys Ther Sci. 2016;28(1):175-180. doi:10.1589/jpts.28.175.

[34] Gross AR, Paquin JP, Dupont G, et al. Exercises for mechanical neck disorders: A Cochrane review update. Man Ther. 2016;24:25-45. doi:10.1016/j.math.2016.04.005.

[35] Gross AR, Goldsmith C, Hoving JL, et al. Conservative management of mechanical neck disorders: a systematic review. J Rheumatol. 2007;34(5):1083-1102. https://pubme d.ncbi.nlm.nih.gov/17295434.

[36] Sarig-Bahat H. Evidence for exercise therapy in mechanical neck disorders. Man Ther. 2003;8(1):10-20. doi:10.1054/m ath.2002.0480.

[37] Verhagen AP, Scholten-Peeters GG, van Wijngaarden S, de Bie RA, Bierma-Zeinstra SM. Conservative treatments for whiplash. Cochrane Database Syst Rev. 2007;(2). doi:10.1002/14651858.CD003338.pub3.

[38] Rajesh Gautam, Jagdeep Kaur Dhamija, Amit Puri. Comparison of Maitland And Mulligan Mobilization in Improving Neck Pain, Rom And Disability. Int J Physiother Res 2014; 2(3): 482-87. https://www.ijmhr.org/ijpr_articles _vol2_3/IJPR-2014-614.pdf.

[39] Kotb R. Mulligan versus Maitland Mobilization in treatment of chronic mechanical neck dysfunction. Published Doctoral thesis, Faculty of Physical Therapy, Cairo University, Giza, Egypt. 2016. http://lib.pt.cu.edu.eg/data\%20musculoskeleta 1\%20 doctoral\%202016.pdf.

[40] Ahmed Mohamed El-Sodany, Mohamed Salaheldien Mohamed Alayat, Ayman Mohammed Ismail Zafer. Sustained Natural Apophyseal Glides Mobilization versus Manipulation in the treatment of cervical spine disorders: a randomized controlled trial. International Journal of Advanced Research. 2014; 2(6): 274-280. http://www.journ alijar.com/article/1965/sustained-natural-apophyseal-glidesmobilization-versus-manipulation-in-the-treatment-of-cervi cal-spine-disorders:-a-randomized-controlled-trial.

[41] Hearn A, Rivett DA. Cervical SNAGs: a biomechanical analysis. Manual Therapy 2002; 7(2): 71-9. doi:10.1054/math.2002.0440. 
[42] Vicenzino B, Paungmali A, Teys P. Mulligan's mobilization-with-movement, positional faults and pain relief: current concepts from a critical review of literature. Man Ther. 2007; 12(2): 98-108. doi:10.1016/j.math.2006.0 7.012 .

[43] AkramAmro, Ina Diener, Wafa' Omar Bdair, Isra' M. Hameda, Arwa I. Shalabi, Dua' I. Ilyyan, The effects of Mulligan mobilization with movement and taping techniques on pain, grip strength, and function in patients with lateral epicondylitis, Hong Kong Physiotherapy Journal, 2010, 28, 19-23. https://doi.org/10.1016/j.hkpj.2010.11.004.

[44] Lawrence Hugh Jones, D.O., Ontario, Oregon the DO, Jones LH. Spontaneous Release by Positioning. 1964; 1:109-116. https://www.jiscs.eu/files/20-SpontaneousRelease byPositioning-LHJones-1964.pdf.

[45] Bodes-Pardo G, Pecos-Martín D, Gallego-Izquierdo T, Salom-Moreno J, Fernández-de-las-Peñas C, et al., Manual treatment for cervicogenic headache and active trigger point in the sternocleidomastoid muscle: a pilot randomized clinical trial. Journal of manipulative and physiological therapeutics. 2013;36(7):403-11. doi:10.1016/j.jmpt. 2013.05.022.
[46] D’Ambrogio KJ, Roth GB. Positional release therapy: Assessment \& treatment of musculoskeletal dysfunctions: Mosby Incorporated; 1997. https://www.scirp.org/(S(351jm bntvnsjt1aadkposzje))/reference/ReferencesPapers.aspx?Re ferenceID=1093867.

[47] Wong CK, Schauer C. Reliability, validity and effectiveness of strain counterstrain techniques. Journal of Manual \& Manipulative Therapy. 2004 Apr 1;12(2):107-12. https://doi.org/10.1179/106698104790825347.

[48] Lewis C, Flynn TW. The use of strain-counterstrain in the treatment of patients with low back pain. Journal of Manual \& Manipulative Therapy. 2001 Jan 1;9(2):92-8. https://doi.org/10.1179/jmt.2001.9.2.92.

[49] Denise Deig. The effects of Positional Release and Stretching on surface EMG Activity of Upper Trapezius Muscles. Master of Science Research Project. Indianapolis, IN University of Indianapolis, 1994. https://www.denisedeig.com.

[50] Korr IM. The neural basics of osteopathic lesion. JAOA, 1947; 47: 191-198. https://pubmed.ncbi.nlm.nih.gov/18910 957. 